\title{
Scientific and Practical Justification of Designing School Uniform
}

\author{
Svetlana Gazimovna Sunaeva ${ }^{1 *}$, Guzel Gazimovna Sunaeva², Tatiana Aleksandrovna \\ Gordeeva $^{1}$, Irina Ivanovna Gerasimenko ${ }^{1}$, and Iuliia Anatolevna Moskovskaia ${ }^{1}$ \\ ${ }^{1}$ K.G. Razumovsky Moscow State University of technologies and management (the First Cossack \\ University), Department of Design and Applied Arts, Moscow, Russia \\ ${ }^{2}$ Ufa State Petroleum Technological University, Department «Project Management and Business \\ Economics», Ufa, Russia
}

\begin{abstract}
The article defines the need for comprehensive research on the justification and development of requirements for this type of product on the part of both today's consumer and production. As a result of such studies, it is necessary to establish indicators for a comprehensive assessment of school uniform providing a high level of its quality, as well as physiological and psychological comfort to the consumer. The study analyzes the opinions of customers and the product range in retail outlets in Moscow that specialize in sales of school uniforms. It was found that $40 \%$ of respondents had serious difficulties in purchasing school uniform kits. It is especially difficult to choose clothes for thin, low stature, and stout children having a body constitution significantly differing from the typical standard. Besides, the fabric properties and model designs do not fully meet the requirements of consumers. The information collected during the research has shown the presence of unsatisfied demand of a large group of consumers of school uniforms and indicated the need for additional research to take into account physiological, hygienic, psychological, ergonomic, aesthetic, and anthropological factors, as well as ensuring the quality of fabrics, and implementing image of school children when creating a school costume.
\end{abstract}

\section{Introduction}

Today, the issue concerning school uniform occupies a central place in discussions about school education in various countries. These discussions are based on reasons related to the strengthening of discipline, manifesting social inequality in clothing, concern for comfortable clothing for school children, etc [1]. But, despite the opinions [2-5] about the infringement of freedom and self-actualization of the school children, there is a noticeable tendency in spreading the school dress code.

In the current context, when the future career depends largely on image, school uniform is appropriate from the standpoint of familiarizing school children with the attributes of business etiquette for working (in the understanding of children, school attendance is similar

\footnotetext{
* Corresponding author: s-svetlana-07@mail.ru
} 
to adult work). The undoubted advantage of wearing a school uniform is also solving the problem of parents as to what to put on their children when sending them to school.

School clothing has significant impact on children's health. Every school-age child spends from six to eight hours a day in this clothing, which makes it necessary to meet increased safety and quality requirements. Poor-quality and unsafe clothing can cause various types of diseases. It is known that some stuff used in the textile industry can cause health problems [6-8]. If all the requirements for the design and production of school uniforms are met, it can be guaranteed that school children's clothing will meet sanitary and hygienic requirements and will not adversely affect their health. Scientifically-based clothing design will ensure proper development, comfort for children of different ages, and even protect them against infections [9].

Today, there is no approved uniform model for school uniforms. The right to decide on the implementation of school uniforms remains with the school administration. The introduction of certain rules by individual school executives without scientific justification may be wrong; besides, it may cause rejection by pupils and their parents.

The purpose of the conducted preliminary study is to identify the need for comprehensive research on the justification and development of requirements for this type of product on the part of both the contemporary consumer and production. These studies should result in determining indicators for the comprehensive assessment of school uniform that would ensure a high level of its production quality.

The development of a comprehensive assessment of school uniform should be based on the study of consumer requirements, identifying the positive role of school clothing in the educational process in general, progressive communication between pupils and teachers, social equalization, and improving the image characteristics of the school in general. In addition to the above, when creating a school costume for children of different ages, it is necessary to take into account physiological and hygienic, psychological, ergonomic, aesthetic, anthropological factors, ensuring the quality of fabrics for school clothing, and the task of implementing an individual image of a pupil.

\section{Methods}

To identify guidelines for further research aimed at improving the children's school uniform, an analysis of the product range, as well as a review of buyers' opinions was conducted in Moscow outlets specializing in sales of school uniforms, namely: Prince Plaza Shopping Center (129a, Profsojuznaya str.), Kaluzhsky School Fair (61a, Profsojuznaya str.), school fair at Capitol Shopping Center, (6, Vernadsky Avenue), school fair at Khorosho Shopping Center, (27, Khoroshevskoe Roadway), Classics (43A Ostrovityanova str.), Peremena, (7A Lipetsk str.), OLMI-school uniform (15 Kirovogradskaya str.), and PoliShinel (21 Bolshaya Tatarskaya str.). In total, 638 buyers were interviewed - parents, who came to buy clothes together with their school children, half of whom were boys.

To achieve the set goal, parameters that affect the buyers' behavior when choosing clothes models were defined based on the literature analysis. These parameters included consumer indicators of the quality of clothing, visual signs of the consumer, models' characteristics, and others. The methods of collecting information (observation and survey) as well as methods of mathematical processing of obtained data were taken from [10]. Calculations of the average values, medians, modes, mean square deviations, and percentile were carried out using the STATISTICA system. A chi-square test ( $\chi 2$ test) was conducted to determine the existence and significance of the relationship, and the Kramer index was used to measure the strength of the relationship. 


\section{Results}

In the course of observations and surveys conducted in specialized stores, it has been revealed that Russian manufacturers of school uniforms, as a rule, produce clothes designed for standard figures. Therefore, in the store, parents can easily choose the uniform for their child, only if his figure is close to the typical standard. Today, there are more and more stout children, while there are no current standards for such children. It is difficult to choose clothes for thin children and those of low stature. The properties of fabrics and design of models do not fully meet the requirements of consumers. As a result, $40 \%$ of respondents had serious difficulties in purchasing school uniforms.

It has been revealed that models from manufacturers of ready-to-wear clothes look differently on children with a standard and nonstandard figure. On stout or too thin, and undersized children they look like inherited from someone. Additional adjustment of the purchased uniform increases its cost and does not always lead to the desired result. This uniform does not smooth out the difference between children in the school team, but on the contrary, causes even more uncertainty to some of them.

It is revealed that some manufacturers of school uniforms are beginning to take into account the physique of children with atypical figures and produce collections of school uniforms specifically for overweight children. Most of the collection consists of spacious models of straight or extended silhouettes, in which the child looks untidy. These models, on the contrary, emphasize the shortcomings of the child rather than hide them. Due to the uneven localization of fat deposits on the stout figure, it is impossible to get clothes that would fit well on a child by simply increasing its volume. Thus, trousers produced for a child with greater stoutness are designed with an increased volume in the waistline area. Such trousers fit well. But when trying on a jacket, several problems arise: jackets are proportionate for children of small stature, while for children with a significant excess weight, a jacket with a suitable volume in the waistline is small in the chest area and the sleeves. Due to these circumstances, many parents of children with the nonstandard figure are forced to order school uniforms in the tailoring shop that is two or more times more expensive than the cost of school uniforms available in the store. The choice of fabrics is also very important for stout children since overweight children release more heat and sweat when perspiring, and thus for them, clothing should be made of natural materials.

The information collected in the course of the study has shown the unsatisfied demand of a large group of consumers of school uniforms, as well as the need for additional research to develop appropriate, nice, and stylish clothing for children of various body types.

\section{Discussion}

It is known that a person, as a biotype, is endowed with certain egalitarian, morphological, metric, psychological, and social characteristics that determine the totality of characteristics and features of everything that surrounds a person and is used by him. If these characteristics correspond to the expectations and requirements of a person, he feels psychological and physiological comfort from the convenience of using them. This led to the emergence of a new scientific area, namely, ergonomics which proved that improving productivity and work quality directly depended on taking into account the anthropomorphological, psychological, and metric characteristics of a person.

The analysis has shown the lack of information that gives a comprehensive picture of the individual as a biosocial type, necessary and sufficient to design objects used by a person. A systematic approach is needed in the creation of an information space about an individual, which would include information about his metric, morphological, and socio-demographic 
characteristics, as well as a psychological type, whose use in the design would increase the competitiveness of consumer products [14].

In the 1950s and 70s, systematic anthropometric studies of the population were carried out in the USSR and CMEA (Council for Mutual Economic Assistance) member countries. These studies resulted in the development of anthropometric standards. Further research have shown that the effect of such standards is limited by 10-15 years [11], which is due to the developmental acceleration of the population. During this period, significant changes are observed in the anthropometric parameters of the population in terms of both leading characteristics and the relations between subordinate parameters. Taking this fact into account, based on new anthropometric studies, in 2001, the Central Research Institute of the Garment Industry has developed new standards with dimensional characteristics of typical figures of boys and girls for designing clothing $[12,13]$. Currently, the design of children's clothing is carried out according to these standards, which again require updating since the research was conducted 20 years ago, and currently, the results are outdated. To ensure all sizes, satisfy the buyer, as well as avoid production losses, along with measurements of figures, the issue arises concerning developing scales for the percentage ratio of types of children's figures by regions.

The existing standards, which include the size characteristics of the selected standard figures, are aimed rather at solving the production issues towards optimizing the number of various sizes of clothes than at increasing customer satisfaction with the size range of produced clothes.

Increased migration processes, changes in demographic characteristics, modifications in size profiles lead to significant changes in the shape of the human body, which cannot be ignored in the production of clothes for various purposes.

Research results [15] show that children's body sizes differ depending on ethnic differences and the time interval between different studies, while the number of overweight children is growing every year [16]. This requires not only changes in standards but also a revision of the scales for the percentage distribution of typical figures by region. Foreign experience also indicates the need for a deeper anthropometric analysis of children's figures [17].

\section{Conclusion}

The resumption of compulsory school uniforms would facilitate the implementation of the main educational functions of the school, such as strengthening discipline, focusing of the school children on the learning process, developing teamwork skills, and forming corporate spirit. At the same time, the uniform limits children's the possibility to compete in clothing, significantly reducing the visual difference between children from families with different material wealth.

Today, a variety of uniforms are offered for school children. Online promotion [18] allows offering a wide range of products that satisfy any aesthetic taste. Besides, consumption in cyberspace provides more opportunities for children [19]. But, at the same time, not all products meet the safety and quality requirements.

The conducted analysis shows that a comprehensive study is needed for the scientific and practical justification of modern school clothing design. It is important to identify the requirements for this type of product on the part of both the today's consumer and production, to develop theoretical and methodological foundations for the representation of not only anthropometric but also morphological, psychological and social characteristics of a child for an objective assessment of the compliance of the designed products with these characteristics. 


\section{References}

1. E. Gentile, S.A. Imberman, Journal of Urban Economics 71(1), 1-17 (2012)

2. N. McCarthy, N. Nathan, K. Hope, R. Sutherland, R. Hodder, Journal of Science and Medicine in Sport 22(2), 94-95 (2019)

3. M.V. Mukhina, E.S. Mukhina, Costumology 2(4), 4 (2017)

4. O.F. Zhukovskaya, L.N. Selivanova, Youth and Science: Actual Problems of Pedagogy and Psychology 3, 34-38 (2018)

5. L.A. Belozerova, O.O. Parfyonova, School everyday life: youth about school uniforms and clothes. Youth of the Ulyanovsk region as an object of socio-humanitarian analysis: analytics, research, opinions (Ulyanovsk, 2019)

6. J. Rovira, J.L. Domingo, Environmental Research 168, 62-69 (2019)

7. J. Rovira, M. Nadal, M. Schuhmacher, J.L. Domingo, Environmental Research 140, 308-316 (2015)

8. H. Zhu, K. Kannan, Science of The Total Environment 710, (2020)

9. A. Wilder-Smith, A. Lover, P. Kittayapong, G. Burnham, Medical Hypotheses 76(6), 861-862 (2011)

10. L.P. Shershneva, S.G. Sunaeva, News of higher educational institutions. Technology of the textile industry 3(261), 79-82 (2001)

11. T.N. Dunaevskaya, E.B. Koblyakova, G.S. Ivleva, R.V. Ievleva, Fundamentals of applied anthropology and biomechanics: textbook for high schools (MGUDT, Moscow, 2005)

12. GOST 17916-86, Interstate Standard. Figures of girls are typical. Dimensional signs for designing clothes (with Changes No. 1, 2) (IPK Publishing House of Standards, Moscow, 2001)

13. GOST 17917-86. Interstate standard. The figures of the boys are typical. Dimensional signs for designing clothes (with Changes No. 1, 2). (Standartinform, Moscow, 2006)

14. L.P. Shershneva, S.G. Sunaeva, Sewing industry 5, $42-44$ (2010)

15. L.R. Prado-Leon, R. Avila-Chaurand, E.L. González-Munoz, Applied Ergonomics 32(4), 339-345 (2001)

16. G. Sumarni Mohd, K. Muhammad Amir, S. Ibrahim Md, I. Mohd Rodi, M.G. Izzuna Mudla, I. Nurziyana, Tropical biomedicine 23(2), 148-154 (2006)

17. A. Widyanti, M. Mahachandra, H.R. Soetisna, I.Z. Sutalaksana, International Journal of Industrial Ergonomics 61, 37-46 (2017)

18. G.G. Sunaev, T.S. Rafutdinov, Internet for startup crowdfunding, In the collection: Modern information technologies in education, science and industry, in Proceedings of the 5th International Conference: 3rd international competition of scientific and scientific-methodological works, International Academy of Informatization, Moscow, Russia (2015)

19. P. Thaichon, Journal of Retailing and Consumer Services 34, 38-47 (2017) 